\section{ADDRESS IN SURGERY.} BY

\section{WILLIAM STOKES, F.R.C.S.I.,}

Profess or of Surgery, Royal College of Surgeons, Ireland; President of the Pathological Society of Ireland.

My first duty and real pleasure is to offer an expression of gratitude for the honour-the great honour - that has been conferred on me and on Irish Surgery in being asked by your Council to address you on an occasion so memorable as the present. Were I called on to address an audience previously unknown to me, though not insensible of its sympathy, my diffidence would be great. How much greater must it be when I know I am speaking to so many fellow-labourers whose work, life-object, and ambition are the same as mine, and many of whom have acquired and deserved far-reaching fame. However, if my diffidence is great, so is also the pleasure, as the honour of being invited to address you comes from the noblest brotherhood in a profession that has yet existed; for such-now celebrating its jubilee-is this Association, the interests and prosperity of which we all have so much at heart.

It must be a source of genuine satisfaction to those who for many years past have taken an active interest in the work of the Association to observe how, first taking root here in the heart of England, its branches now extend not only over the three divisions of the kingdom, but also stretch out widely and luxuriantly to our great colonies, east and far west-wherever, in truth, the flag of England is looked upon with affection and pride. Well has our great brotherhood fulfilled the and expectations of its distinguished founder, Sir Charles Hastings; for, as it had its birth in the "faithful city", so it has proved faithful in many good and noble ways - faithful in removing professional jealousies, and softening asperities-faithful in protecting with its broad and strong shield those among us who may have been cruelly and unjustly attacked-faithful in its efforts to raise the social status of our profession-faithful in its attempts to extricate public opinion from the quagmires of sentimentalism and folly-faithful in aiding and encouraging the scientific vanguard of our profession.

But, great as have been the results of these efforts of the Association, much yet remains to be achieved. I should like to see loyal and hearty co-operation with the universities, the medical and surgical corporations of the United Kingdom, and the General Medical Council, to raise the standard of Arts education for all joining our profession, by establishing conjointly an examination in Arts which every one, except those with university degrees, should pass previous to commencing the study of medicine. I should also like to see a consolidation of the great medical and surgical teaching power that exists in our metropolitan centres, but which, owing to the multiplicity of small schøols in them, is, to a great extent, lost to the profession and to the public. Instead of urging the establishment of additional schools, it would be far better to endeavour to bring about such an amalgamation as I have indicated, and co-operate with those who wisely think that among the chief desiderata in our profession is a larger amount of training in an university where the first phases in the life of a medical student can best be spent, viz.-first, the preliminary general, and second, the preliminary scientific education. I am strengthened in this conviction by the fact that during the Visitation of Examinations recently conducted for the General Medical Council, in which I had the honour of being associated, the Visitors frequently otserved candidates for the diplomas of our corporations whose general and scientific culture was far below what anyone joining our profession ought to have.

The portals of many of the universities have recently been widened, enabling those to avail themselves of the advantages, social as well as intellectual, which an university affords, who a few years since would have been wholly precluded from so doing. In giving these facilities, Oxford, where the natural sciences were too long prescribed and discouraged, is specially deserving of gratitude. Away from the turmoil and distractions of a great metropolis, the sciences ancillary to, as well as those that are the basis or foundation of, medicine, such as human and comparative anatomy, physiology, chemistry, and histology, can best be studied, aided by all the collateral advantages and noble traditions of an historic university. Such training would assuredly give a healthy impulse and scientific direction to the practical work of a student when he leaves the university to complete his professional studies at a metropolitan school. The universities, especially those in or near the smaller provincial towns, are quite unsuitable for complete practical schools of medicine and surgery, the available material being-having regard to existing modern requirements, and especially as regards pathology - necessarily inadequate.

Having for several years been a surgical examiner in the Queen's University in Ireland, I was forcibly impressed with the truth of the view that, for the practical teaching of surgery and pathology, universities in the smaller provincial centres are hardly able to afford adequate material for the student to acquire a sufficient knowledge of these subjects. The function of universities, at least those so situated, in relation to medical education especially, should be that of great scientific schools, and not centres for practical clinical study. I feel confident the day will come, when the wise and far-reaching policy of those who have held and maintained such views will be recognised, and acknowledged to be correct.

I am strengthened in these views from the knowledge that they largely coincide with those of one long and intimately associated with the cause of medical education in this country-I allude to the distinguished Regius Professor of Medicine at Oxford and President of the General Medical Council, whose great and unselfish devotion to the best and highest interests of our profession must ever command our unqualified admiration and respect.

It has hitherto been customary for my predecessors at the annual meetings of the Association, either to give a résumé of the most recent advances in surgery, and discuss some particular theory or mode of practice on which surgical opinion is more or less unsettled, or dwell on those topics that have proved of special interest to himself. On the present occasion, one which should be marked meliore lapillo, to give present occasion, one which should be marked meliore lapillo, to give century would be a task not alone difficult, but, in truth, impossible in the time at my disposal. I purpose, therefore, to dwell on some few topics of great general interest, involving questions still unsettled, and which have more particularly engaged my attention.

However, though a detailed retrospect of the surgery of the past half century is here impossible, let us, like travellers who enjoy the happy toil of climbing an Alpine steep, and who at times pause to look back and take a panoramic survey of the country traversed, see the giddy heights that have been scaled and the difficulties overcome, contemplate the chief advances in our art, the obstacles and opposition the breaking of the fetters that so long bound it to a blind empiricism. What have been these advances? The list is a goodly one, and the mere enumeration of them would alone occupy the hour at my disposal; but I may mention a few of those that stand out most boldly in relief: The abandonment of an indiscriminate blood-letting in almost every form of acute surgical disease, of a reckless use of mercury in the treatment of syphilis, and of setons and moxæ in hopelessly irremediable articular and other diseases; the introduction of the pressure treatment of aneurysm by Bellingham, Todd, and Hutton; of drainage in the treatment of wounds and abscesses by Chassaignac; of metallic sutures and the perfecting of the operations of vesico-vaginal fistula by Marion Sims; of lithotrity by Civiale, Thompson, and Bigelow; and of stricture by Syme, Wheelhouse, Maisonneuve, Perréve, and Holt; the rénaissance of joint-resection by Crampton, Syme, and Ferguson; the renaissance of joint-resection by Crampton, basis of ovariotomy by McDowel, Clay, Spencer Wells, and Keith; of bloodless surgery by Esmarch; of skin-grafting and sponge-grafting by Reverdin and Hamilton; and of osteotomy in genu valgum by Ogston; improvements in methods of amputation by Bell, Teale, Carden, Syme, and many others; also the operations of gastrostomy, excision of the pylorus, of the spleen, the kidney, supra-pubic excision of the uterus, laparotomy, and cholecystotomy. In connection with abdominal surgery, I would also allude to the recently published able essays by Sir William Mac Cormac and Dr. Marion Sims, the latter paper dealing mainly with antiseptics and drainage in gun-shot wounds-these being, in Sir James Paget's opinion, "the most important perhaps of all the provisions to be made in healing wounds." Again, we have torsion in the treatment of hæmorrhage-a method to which such an impulse has been given by Mr. Bryant; and the treatment of aneurysm by arterial ligation, without injury to the deeper structures of the vessels, by the methods of Porter and Barwell. In two cases I adopted Porter's method, using a wire, deligating the femoral artery in one, and in the other the abdominal aorta, Barwell's ligature-made from the aorta of an ox-a method recently tested in the Richmond Hospital by my colleague, Dr. Thomson, who deligated the arteria innominata for subclavian aneurysm. Again, we have, in the treatment of fractures, immovable splints, and 
improved methods of extension by weights, or more perfectly by screw action; of manipulation in the treatment of luxation; and, in spinal disease, the use of the plaster-jacket of Sayre.

I need not dwell on the complete revolution in ophthalmic and aural surgery that has occurred, and of the light that the ophthalmoscope of Helmholtz has shed, not alone on ophthalmology, but on pathology in its widest sense; or on the other instruments of precision constantly made use of. Memorable as these advances would make any era in the history of surgery, they all pale before three I have yet to mentionadvances which the surgical historian will doubtless point to and emphasise as the three giant strides that the past half century has witnessed. I allude, first, to the discovery of the means of banishing pain during the performance of surgical operations ; secondly, to the restoration of diseased or injured bones and joints necessitating resection; and, thirdly, the enunciation of the principle and establishment of the practice by Pasteur and Lister of antisepticism in the treatment of wounds. When we reflect that so large a part of these changes in surgical principles and practice has been due to the genius and honest labour of so many workers in the United Kingdom, we may well feel a pardonable pride in British Surgery, and confidence in the coming triumphs of our art.

To anæsthetics, antiseptics, and osteogenesis, together with a few cognate topics, I would therefore now invite attention.

Whatever anæesthetic the surgeon selects-whether it be chloroform, ether, or both combined, bichloride of methyline, or nitrous oxide gas -we must admit that, even with the most careful precautions as regards the condition of the patient generally, the anæsthetic selected, the amount of it used, and the mode of its administration, the gauntlet of peril has still to be run. In truth, it is hardly to be expected than an agent which can so rapidly and completely paralyse our senses should not be attended with peril. Of the two anæsthetics, however, that strgeons as a rule mainly rely on-ether and chloroform-much has of late been done to diminish risk by limitation of the amount of the anæsthetic used ; by the gradual introduction of it into the system; by the avoidance of ether in infancy and extreme age, in the puerperal state, in hysteria, and also when there is reason to suspect the existence of any acute or chronic form of renal or pulmonary disease. In the use of chloroform the ever-present risk of cardiac paralysis appears to be increased when any functional or organic disease of the heart is present, and is, therefore, in such cases, distinctly contraindicated.

Although the number of accidents connected with the use of anæsthetics is fortunately very limited, still I feel sure that by more accurate knowledge of the facts I have mentioned, by entrusting the duty of administering anæsthetics solely to persons of experience and judgment, and by a stricter adoption of the rule so happily formulated by $\mathrm{Mr}$. Jonathan Hutchinson in reference to the desirability of using chloroform in cases below six and above sixty years of age, the number of these regrettable accidents would be still further largely diminished. In the majority of cases, however, I would unhesitatingly prefer ether. In using it, there is greater economy of time ; it is, with the necessary precautions taken, safer; there is, as a rule, less sickness, and return to sensibility is slower. To obtain these advantages-which, with others, have been so well and systematically formulated by Mr. Teale (BRITISH MEDICAL JouRNAL, March IIth, I882)-regard must be largely had to the method employed of administering it ; and I am of opinion that one in which the air is rebreathed by the patient, as in the inhalers of Morgan, Ormsby, and Clover, should be preferred, as so great an economy is effected thereby, not alone of ether, but of what is of far greater importance, of heat in the air-passages, the inspiration of a large quantity of cold ether vapour tending to induce respiratory syncope.

In these instruments, the inhalation of a combination of ether-vapour and carbonic acid gas occurs. It does not, however, appear to be clearly ascertained whether in this fact there is the introduction of an additional element of danger or not. Opinion on this point is still greatly divided. One would say, $a$ priori, that there was; but experience has not established the fact.

Of the countless benefits conferred on man by anæsthetics, of the suffering prevented, of the absence of all anticipatory fear of suffering, of the happy subsequent oblivion of all the horrors and details of the operation, and of the diminution of shock, it is unnecessary to speak. To these must be added the advantages which enable the operator to act with a deliberation and calmness, enjoying freedom from anxiety and care he could not otherwise have. Advantages such as these cannot be overestimated, being as signal to the patient and the operator as they are to surgery.

Although there is traditional evidence that the anæsthetic properties of certain plants - notably the mandragora-were known to the physicians of ancient Greece and Rome, and that in I 800 our distinguished countryman, Sir Humphrey Davy, mentioned that nitrous oxide was "capable of destroying physical pain, and may be used with advantage during surgical operations", still it was not until 1846 that anæesthetics came properly within the domain of practical surgery, when Morton, in the Massachusetts General Hospital, first demonstrated the possibility of inducing anæsthesia by the inhalation of ether.

To Simpson is undoubtedly due the credit of discovering, in 1848 , the anæsthetic properties of chloroform, and in giving an impulse to its adoption, such as his brilliant intellect alone could give; but still we must cordially, willingly, and gratefully endorse the opinion of Professor Gross, that, "if America had contributed nothing more to the stock of human happiness than anæsthetics, the world would owe her an everlasting debt of gratitude".

Considering that the treatment of wounds is, in Professor Humphry's words, not merely "the first stone, but also the corner-stone of surgery", antiseptic practice should rank, in my opinion, as the greatest of the surgical advances that the past half-century has witnessed. It deserves a special attention, not merely on account of the results of its adoption, but also because surgical opinion is still so divided about it: an unsettlement to which an impulse has been given by Mr. Savory's remarkable address at Cork, and by the observations on the value of carbolic spray made by Mr. Lister himself at the International Medical Congress last year. As regards Mr. Savory's denunciation of Listerism, I would say that, after reading it, and also the able reply to it by my colleague, Dr. Thomson, one cannot but come to the conclusion that, when the address is stripped of all its brilliant eloquence and rhetorical decoration, two facts are, to our surprise, brought clearly to light. One is the admission of the germ-theory of putrefaction; and the other, that the method of dressing employed by Mr. Savory is essentially antiseptic, consisting as it does of many of the features that characterise Listerian dressings; for example, carbolised catgut ligatures, carbolised oil, drainage, and washing the wound with a weak permanganate of potash lotion or "some other potent antiseptic". Now, as the author of the reply to which I' have referred properly asks, "Is this method fittingly characterised by its simplicity and the entire absence of all novelty?"

In reference to Mr. Lister's statement on the value of carbolic spray, about which there has been so much unfortunate misconstruction and misunderstanding, I would certainly say he did not surrender his position in any way. He did not, as was said to me, in terms more picturesque than accurate, by an eminent surgical friend on that occasion. "inter antiseptic surgery and then sing a dirge over it". On the contrary, he stated that he looked forward to ohtaining a more perfect and convenient mode of asepticism than that afforded by carbolic spray.

Considering the subject from a purely practical point of view, it appears of little consequence whether we accept the views recently discussed by Dr. Burdon Sanderson, or those of Ogston and Hueter, the former maintaining that the inflammatory exudates of a wound do not depend primarily on the contact with them of atmospheric organisms, but that their secondarily infective character does; in other words, that atmospheric organisms per se are not necessarily a source of danger, nor do they predispose to the formation of inflammatory exudates, but that they do exercise a baneful influence on the latter by rendering them infective. To quote his words, "they are not so much mischiefmakers as mischief-spreaders". Two distinct functions are attributed by Burdon Sanderson to these organisms; one " of developing what may be called the phlogogenic infection, and that of conveying it to all parts of the body." Ogston and Hueter, on the other hand, maintain, and furnish strong arguments for their views, that septic organisms are primarily the sources of all the inflammatory and other troubles to which wounds are liable, and that, under aseptic conditions, these dangers can be avoided. It is not my purpose to discuss which of these theories is likely to be correct ; for, whichever view we adopt, the necessity for thorough antiseptic precautions remains the same. Assuming that Burdon Sanderson's theory be correct, and that inflammatory exudation is the physiological and harmless outcome of a traumatism, can we say how long it will remain so? How long or how short a time it may take to become infective, whether days, hours, minutes, or seconds? Is it not in accordance with all reasonable probability that the time must be ever-varying; and, assured of this, should we not take every precaution to prevent the entrance, neutralise or destroy the noxa or septic agency? Have we any means of estimating the power of resistance to the action of septic agencies, or of telling when will commence those chemical putrefactive changes, the sources of the disasters of surgery which antiseptics so powerfully strike at, prevent, and destroy?

The essentially weak point in the persistent and obstinate opposition to Listerism is the almost universal admission of the truth of the germ-theory of putrefaction. If the fantastic theory of heterogenesis 
bad not long since been swept into the deserved limbo of other exploded doctrines, there would be some scientific standpoint for those opposed to Lister's theory and practice. But not having this, and admitting the truth of the germ.theory of putrefaction, they surrender their position. An attempt has been made by Mr. Lawson Tait to draw a distinction between the effects of germs on dead and living tissues, the only serious consequences being, it is alleged, those which result from their introduction into the system through the medium of dead tissue. Such is the contention. In a word, it comes simply to this : that, if the dead tissue-factor were non-existent, the organisms would remain harmless; if, on the other hand, it be present, they become burtful. But those who hold this view, ignore the elementary fact that there never was a wound, and especially one in which ressels are tied or twisted, in which dead and living tissues were not at once brought into contact. Assuming, however, that this was not the case, has it not been shown on clear evidence by Dr. Burdon Sanderson that septic agencies generated in the organism may induce idiopathic inflammation without the medium of dead tissue? Also that, in acute peritonitis, septic organisms can, through the medium of the lymphatic vessels, be conveyed into the blood-streams, and, to use his words, "carry with them a phlogogenic virus, by virtue of which, wherever they lodge, they become the starting points of infective abscesses." Again, that similar phenomena are observed in connection with ulcerative endocarditis, confirming the observations of Weigert that, in variola, they find their way "in myriads" into the circulation, and eventually find a resting place in the capillaries of the internal organs, where they become nuclei of infective abscesses (BRITISH MrDICAL JoURNaL, April I5th, 1882).

If such phenomena are capable of being produced in the organism without the intervention of dead tissue, which appears to stimulate septic agencies to such pernicious activity, there is certainly all the more reason for using means to neutralise or destroy them, when, as in all wounds, dead and living tissues are brought into contact.

Those who advocate and practise what they are pleased to term a " modified" antiseptic spstem, attempt, in fact, in a roundabout, clumsy, inefficient way, to do precisely what those who practise Listerism achieve by means which are the outcome of accurate scientific research.

The aim in both cases is to neutralise or destroy the agencies which predispose to, and produce the materics septica-in the one instance by numerous uncertain and often inefficient methods; and in the other, by the unerring artillery of chemical agency.

Among many depreciatory remarks that have been made in reference to Listerism, is one based on its alleged want of originality. It has been stated that both antiseptic principles and practice were understood, recognised, and appreciated by many of Mr. Lister's predecessors and contemporaries. Foremost among the latter, M. Maisonneuve has been mentioned. Having attended the clinique of that eminent surgeon for two sessions, in 1864.5 , I am in a position to mention the nature of the wound-dressings then employed by him. With a large syringe, a quantity of a weak solution of "acide phenique" was ap. plied to the wound; then a piece of linen or cloth, perforated with numerous openings and covered with a yellow-coloured grease, was placed on the wound, secured by a dry compress and bandage. Such were the antiseptic dressings of which Lister's, it is alleged, are only a somewhat complicated, expensive, and, in many cases, dangerous reproduction.

It has been stated that ovariotomy should be considered the touchstone of the efficacy of the antiseptic treatment of wounds. I do not think so (although my successes in ovariotomy date from the time I adopted the system), and for the reasons given by Professor Lister. First, the disposition of a large serous membrane to absorb rapidly the plasma from the cut surface, the absence of tension, the high vital power of the peritoneum in uniting after being wounded; and, lastly, that bloody serum is an unfavourable medium for the growth of micro organisms, a fact directly at variance with the dictum of Keith, that it is the "enemy of the ovariotomist." One of the best tests, if not the best, for the value of antiseptic practice is resection of the knee-joint, as there are so many circumstances that militate against immediate union being obtained after it. In the first place, the cases requiring so formidable an operation are, as a rule, in a condition of great physical exhaustion consequent on long confinement, and probably protracted suffering of mind and body. The wound is of necessity a large one the operation occupies a considerable time; two large freshly cut bone surfaces are wade, between which union is to take place; and, lastly, there is the great difficulty of keeping, no matter what appliance be adopted, the limb absolutely at rest during the process of union. Before the adoption of Listerism the surgeon anticipated that four, six, or eight months, or longer, would elapse before union took place, and it
Tas al ways a subject discussed at consultations on these cases, previously to operation, whether the pratient would have strength to endure so protracted a suppuration. As an illustration of how changed matters are now, in a series of fourteen of my cases of excision of the knee-joint, the wounds in nine of them united without a trace of pus production: and in the last of them only two dressings were required subsequent to the one applied at the time of the operation, and in seven weeks after the patient was up and going about. Another antiseptic triumph was the case of $a$ boy with extensive necrosis of the fibula, sinuses, and sup. puration existing at the time of the operation. I excised subperiosteally the diaphysis of the fibula, and the case pursued a perfectly aseptic course, the evidence of new bone-formation being also incontrovertible. From the fact of there being no pus production subsequent to the operation, notwithstanding the pre-existence of suppurating sinuses, a special interest attaches itself to this case. I can only account for this exceptional circumstance as a result of the careful washing of the sinuses by carbolic acid and zinc chloride solutions. A still more remarkable case was that of a youth who was under my care last November. He trod on a triangular piece of glass which, having passed deeply into the sole of his foot, was with difficulty extracted. An acute suppura. tive inflammation, involving the ankle-joint and extending as far as the knee was the outcome of the injury. There was indicated by both pulse and temperature very high fever, and the condition of the patient was most critical. I made free incisions under the spray on both sides of the ankle-joint, and gave exit to pus and synovia in large quantity. Into these openings I injected a weak solution of eucalyptol and inserted Neuber's drainage tubes. Next day I found pulse and temperature normal, and from this the case pursued an aseptic course, and in less than a month after, the patient left the hospital, the foot being in a perfectly normal condition, all motions of its joints being free and un attended with the slightest stiffness or pain. In another case, I cut down on an ankylosed hip (the limb being so flexed as to be perfectly uselcss to the patient), and divided the neck of the femur with an osteotome, and straightened the limb. The wound healed without pus production, and a freely movable false joint was formed, and the patient is able to walk several miles without inconvenience.

Another antiseptic triumph was obtained in two cases of amputation at the hip.joint. In one of these there were pre-existing sinuses and profuse suppuration, and, notwithstanding, I succeeded for eight days, during the most critical period of the patient's convalescence, in keeping the wound aseptic, and preventing the occurrence of surgical fever. The result in the second case was more remarkable; not only during the healing of the wound was there no pus production, but pulse and temperature hardly ever rose beyond the normal standard. The skin was unbroken, and on the evening previous to, and also on the morning of the operation the patient had a eucalyptol bath. Looking at these few cases-few, not because I could not largely supplement them, but because they are sufficient for my present purpose-I would ask could such results have been obtained previous to the Listerian teachings of the principles and practice of antiseptic surgery? There can be but one reply-impossible.

In giving the details of these antiseptic triumphs I may be considered dogmatic and egotistical. If so, I regret it, for nothing could be further from my aesire; still less would I seem captious or actuated by any partisan spirit. I have mentioned them solely through a desire of having the truth recognised and established, and because personal ex. perience is the soundest basis of honest conviction.

As regards the hygienic effects of the practice, I may mention some facts of interest noticed by me and my colleagues in the hospital io which I am attached. The building is a very old one, and was not constructed originally for a hospital. None of the more modern arrangements, now considered so essential, as regards heating, light, ventila. tion, etc., exist. It is situated in a poor, very densely populated part of the city, with tenement houses, dairy yards, cattle sheds, and stables in its neighbourhood; and some of the houses in its immediate vicinity have been designated by the Medical Officers of Health as "fever nests." When I was a student there erysipelas and pyæemia were not unfrequently cbserved after operations even of no great magnitude ; hospital gangrene too, I have seen several instances of -in fact, these three diseases constituted a grim trio, of which the surgeons had not unnaturally a dread. Let it not be thought that the occurrence of these was in any way to be attributed to want of care and attention to cleanliness. No cases could in this respect be more conscientiously or carefully managed. What now exists? Hospital gangrene is an extinct disease, nor have we observed, during a period extending over six years, a single case of erysipelas, septicæmia, or pyæmia following an operation in which the practice of Lister was accurately carried out; accuratcly, for everything depends on that. The practice has been well compared to a coat of mail, which secures the wearer so 
long as it is perfect, but any missing link in which may admit the lethalis arundo.

Similar testimony to what I and my colleagues can state has been given by many foreign surgeons of eminence, among whom I may mention Von Nussbaum, Bardeleben, Thiersch, Von Langenbeck, Volkmann, Esmarch, Saxtorpf, Championnière, and many others.

Much blame has been cast on Professor Lister and his followers for not having had recourse more largely than they have done to statistics, to prove the superiority of antiseptic practice over the older and alleged simpler methods of wound-dressing, and to show that, by the use of the former, we are more independent of those epidemic influences that have hitherto been so pregnant with disaster in operative surgery. It is not my purpose here to discuss the value of the surgical statistics that have been adduced to prove that the alleged simpler methods of wound-dressing are of equal efficacy to those of Lister, especially as most of them have a strange family resemblance to the latter; but this I will say, that whatever value is to be ascribed to accumulated figures - often sadly fallacious - that value is not to my mind greater, or at all so great, as the often repeated occurrence of test-cases, recorded daily, not alone in a particular hospital, town, or country, but in hospitals in all climates and conditions, where the hygienic surroundings are brought to the highest known degree of perfection, as well as where they are in a condition the most deplorable. Such records carry more weight with me than the inflated statistics from any particular hospital, or the alleged results obtained without antiseptics after any special operation or group of similar operations.

Mr. Savory dwelt at great length on the statistics of operations at St. Bartholomew's Hospital. These were, no doubt, very important, and probably carried conviction as to the soundness of the conclusions drawn from them to the minds of most of his hearers. In various points, however, they were unsatisfactory to me. For example, among others, no mention whatever was made of the operation of ovariotomy, in which procedure, although some regard Listerism as positively injurious, still many others take an opposite view, and think with myself that it has probably done more than anything else to diminish the mortality of the operation. It was unfortunate, in $\mathrm{my}$ opinion, that the facts in respect of this particular operation at St. Bartholomew's Hospital, before and after the introduction of Listerian antiseptic practice, were not stated.

Although I do not regard surgical statistics with the reverential awe that some do, who look upon them, in fact, as a sort of tribunal beyond which there can be no appeal, I observe that in a record of upwards of six hundred operations performed by myself and my colleagues at the Richmond Surgical Hospital, during the past three years-an institution which I have already spoken of as being hygienically in so unsatisfactory a condition -the mortality was 3.6 per cent. ; and there was not a single case in which Listerism was accurately employed that was followed by any infective disease.

The discovery of anæsthetics, and the means of inducing osteogenesis, have largely widened the field of practical surgery. When we consider the revolution that has taken place, since the introduction of antiseptics, in the treatment of compound fracture, of abscesses-especially those symptomatic of bone-disease- of bursal tumours, of congenital as well as acquired osseous deformity, of ununited fractures, including those of the patella and olecranon, of foreign bodies in joints, of hæmorrhage and aneurysm by antiseptic ligature, and of various diseases and injuries of the abdominal organs indicating the operations already mentioned, this may, I think, be said with even greater truth. To these may also be added certain thoracic affections, such as empyema, pericardial effusion, and pulmonary abscess, by which the wide gulf that so long existed between medicine and surgery has been to a great extent bridged over-uniting them together firmly, strongly, and for ever.

It is a subject of regret to me that so many surgeons of long experience, and of great and deserved eminence, have been found who have either been disposed to discredit a thorough antiseptic practice altogether, or to have given but a very lukewarm adherence to it. Much allowance, however, must be made for the well-known and not unnatural dislike to change on the part of those, many perhaps advanced in life, whose early training has been so different to that now a vailable. With their successors, more fortunately circumstanced in this respect, the case is different. Their condemnation has, I fear, been the result of apathy, indifference, and, in some instances, indolence, preventing them taking the trouble to learn either the principles or the details of the practice.

Representatives of what may be termed a Rip Van Winkle school of surgery, they differ in one respect from the mythical personage just alluded to. His ignorance of what was going on about him was the result of involuntary unconsciousness. But his surgical analogues, I fear, wilfully refuse to see, wilfully refuse to acknowledge, and wilfully refuse to recognise what has been and is being done. Strangely unmindful of the fact, that honest scientific toil has never yet proved other than fruitful of good, they promulgate views ever acceptable to ignorance and indolence; and make the land ring with the false and cruel tale that the value of Listerism is a delusion, a bubble, a shadow, and a myth - at once expensive, complicated, and poisonous. If, on this latter account, it is to be rejected, then may we, with equal justice, say : "Away with anæsthetics; away with opium, mercury, belladonna, with half, or more than half, the means at our disposal for alleviating human suffering and prolonging life."

In the interests and for the credit of British surgery, it is time so unrighteous a warfare should cease. It is time that the irritating dust of an unreasoning prejudice should be swept away. It is time that one of the greatest discoveries and boons to surgery this century has produced should be universally recognised as such. It is time that its dis. coverer and exponent should be acknowledyed as one of whom it may well be said-

$$
\text { ".With Genius Nature joins in everlasting covenant still, }
$$$$
\text { The promises of one, the other fails not to fulfil." }
$$

The methods adopted for bringing about a regeneration of bones and joints necessitating resection on account of injury or disease, constitute an advance in surgery of such interest and practical importance as to distinctly merit special consideration. To adopt a measure by which the main support of a limb, when diseased, and not only rendering that limb useless, but also perhaps imperilling life by pain and exhaustive suppuration can be removed, with not a mere probability, but, in many instances, almost a certain confidence that it will be restored to the patient, is a triumph than which it is hard to conceive one of greater importance among the developments of modern surgery. The subject has been of keen interest to me for many years, since the time when, in 1865 , I witnessed in Lyons many of M. Ollier's experiments, and subsequently repeated them. Strongly impressed by what I then learned, I have since in practice, as suitable cases presented themselves, adopted periosteal preservation in various operations on bones and joints, a procedure with which the names of the eminent surgical trio, Syme, Langenbeck, and Ollier, must for ever be associated. The operative measures on which my experience is based are resections of the elbow, shoulder, and ankle-joints; resection of the diaphysis of the fibula in its entirety; resection of the greater portion of the ulna; of metatarsal and metacarpal bones; and, lastly, of transplantation of periosteum, as a part of the so-called Indian rhinoplastic operation. Still, though the good results obtained by this practice are, in properly selected cases, not open to question, there can be no doubt as to the existing unsettled condition of surgical opinion in reference to the value of the procedure. This, I believe, arises from a twofold cause, one being traumatic, from insufficient care being taken during the detachment of the membrane, and the second, the non-differentiation on the part of surgeons of the cases likely to be benefited, and those in which the adoption of the practice is, as a rule, attended with disappointing results. As to its value, when the membrane is comparatively healthy, and the patient young, there can be no question. The activity of bone production and other signally gratifying results of the practice must be acknowledged when performed under these circumstances. These results, however, are not so striking when the patient is an adult. In some cases, no bone production whatever is observed, and in others the osteogenetic process is slow, the product weak and liable to become absorbed. It should also be borne in mind that, in early life, the membrane has a dual function; one, that of increasing the thickness of bone, and the other the repair of waste. In adult life, it is mainly confined to the latter. This rule, however, is not without exception. One instance I can recall of a man, aged 42 , on whom I performed a resection of the upper end of the humeras on account of carious disease. The result was eminently satisfactory; not only was there a reformation of the bone removed, as evidenced by comparative measurement, but also a pseudo-arthrosis so perfect as to euable him now, as I have recently learned, to use his spade, to plough, and perform with efficiency all the ordinary duties of an agricultural labourer.

Another point worthy of consideration is the value of the practice in adults and children when the membrane is found to be thickened and pulpy. Among the former, as mentioned by $\mathrm{M}$ ' $\mathrm{E} w e n$, the osteogenic layer is, as a rule, found to be destroyed, the outer layer thickened, vascular, and lined with granulation-tissue, which soon undergoes fatty degeneration. From such a condition, no bone production could possibly be anticipated. On the other hand, a thickened, vascular, cell infiltrated, softened condition is not incompatible with its osteogenic layer being intact, and its activity in bone production unimpaired; in truth, not unimpaired, but exalted, as we observe in acute necrosis, and also in the development of syphilitic nodes. The condition of fatty degeneration of the osteogenic layer is found among both adults and 
children, but more frequently among the former. When found among the latter, the cases are, as a rule, badly nourished, anæmic, weakly, and scrofulous. The thickened, vascular, but intact condition of the membrane is what is observed among young persons, and its preservation, therefore, is obviously indicated. In adults, it is rarely observed.

The efforts to produce bone in experiments on the lower animals by periosteal transplantation have not been attended with any very marked success, nor have similar attempts in man been specially encouraging. In only one instance did Ollier obtain distinct evidence of bone formation from grafted periosteum. In the Indian rhinoplastic operation, I have undoubtedly succeeded, after transplanting the membrane from the frontal bone, in satisfying myself of the existence of bone reproduction. When left attached to bone, as in Von Langenbeck's modification of this operation, the result has not been so good, owing to the liability to necrosis of the transplanted or detached portions of bone.

As regards bone transplantation I cannot speak from any personal experience; but, in connection with this all-important subject, I must allude to the great stride made in this direction by Dr. M'Ewen of Glasgow. The case of inter-human osseous transplantation in which over two-thirds of the shaft of a humerus was restored, and an account of which was communicated to the Royal Society last year, is one which must stand out in bold relief in the history of this new departure in operative surgery-one which is with many others an outcome indirectly perhaps, but not the less a result, of antiseptic surgery. For the experience derived from observing the progress towards good union and without pus production of bad compound comminuted fractures when pieces of bone completely separated, and even detached from periosteum, have, after being antisepticised, been replaced, lived, and eventually united to the neighbouring osseous structures, tends, as $\mathbf{M}^{\prime}$ Ewen has pointed out, to show the probability of transplanted bone living. The practice of interhuman osseous transplantation is one which of necessity is applicable to only a very limited number of cases, and the means of carry ing it out must rarely be available, as fresh, human, healthy osseous transplants cannot often be obtained. The case, however, which I am glad to say I had an opportunity of examining, is so pregnant of interest, and so suggestive, that it must serve as an incentive to further effort to guide and encourage those working in this direction.

The subject of periosteal preservation naturally leads to that of joint resection, in which it has played so important a rôle. The resection, however, I wish more particularly to allude to, namely, that of the knee, is less associated with periosteal preservation than the other excisions. The surgical merits of this operation being so important and so vexed a question make it worthy of special notice. I will not, however, dwell at any length on the subject, having regard to the fact of its having been recently so ably handled by Mr. Holmes at the meeting of the Association, at Cambridge.

It is not surprising that its position as one of the resources of surgery is not yet generally appreciated, and that controversy should still so hotly rage about it, when we reflect that the majority of surgeons have hitherto regarded it in the light of a substitute for amputation. In doing so, a grave error has been committed, for the indications for one of these operations should never be those for the other. If we accept the view that tuberculosis, more particularly as regards its articular manifestations, is primarily local, but, as shown by Klebs, like cance: or syphilis, transmissible and capable of producing a general infection, a view that mainly from a clinical standpoint I accept, then the question of the importance of early resection at once comes to the front. But it may be and has been said, notably by Mr. Macnamara of London, that in the early stages of strumous articular disease, affecting mainly the synovial membrane, that rest, good diet, and "convalescent homes" will suffice to cure the disease at this period of its development. I admit they may, but in a very small proportion of cases. I would be equally ready to admit that in a small proportion of cases intermittent fever may get well without quinine, syphilis without mercury, iritis without belladonna, and primary union without antiseptics. Who, however, would maintain that, because in a small minority of cases the desired results are obtained without such aids, that therefore it was open to discussion whether they should not be abandoned altogether? In dealing with a broad question, such as the surgical merits of kneeresection, the question as to a treatment that is only applicable to a small fortunately circumstanced minority, and the advantages of which are very problematical, should scarcely be mentioned when a practice is under discussion applicable to the masses of mankind in all countries, climates, and conditions, without convalescent homes at their disposal, or ways of getting constant skilled aid in carrying out an "expectant" treatment for two or three years-a treatment from which no better result than ankylosis can be expected. In patients, too, with a predisposition to secondary tuberculous deposits, the probability of the recurrence of the disease after "expectant" treatment must be borne in mind.

From my experience, I believe that excision of the knee should not be looked on as a last resource, but that the operation should be performed before any profound organic changes take place, and that when the following conditions are fulfilled: An unbroken skin, an all-important factor; the disease limited, and to the soft structures, an efficient method of fixation applied, and a rigid system of antiseptic dressing of the wound adopted, primary union may in the great majority of cases confidently be anticipated. The alleged unfavourable results of the operation, especially in early life, are distinctly opposed to my clinical experience.

In another group of operations-namely, in amputations-the preservation of periosteum is, according to Von Langenbeck, Trélat, and others, attended with advantage. The formation of a periosteal curtain to cover the cut surface of the bone and its medullary canal is believed to act as a shield or barrier against septic agencies, and diminish the chance of the occurrence of some of the secondary calamities, notably osteomyelitis, following amputations. The method I have in some instances adopted, and with success, is, making a somewhat quadrilateral-shaped flap at the membrane and letting it fall over the cut surface of the bone. Another method, that of M. Trélat, is to detach the membrane all round the bone for fully an inch below the point where the bone had to be divided, making, in fact, a sleeveshaped flap. This plan must, however, materially protract the operation.

This leads me to consider some other comparatively recent improvements in the operation of amputation, and to bear my testimony to the great advantages to be derived from the adoption of the principle of long anterior flaps, the chief credit for establishing which belongs to the late Mr. Teale of Leeds; and it is a source of pleasure to me that the advantages from his method of amputation were so soon, and con. tinue to be so fully recognised and appreciated in Dublin. In reference more particularly to thigh-amputation, I cannot refrain from noticing the procedure in which the principle of the long anterior flap is embodied-namely, the "single flap" or "single-skin flap" operation of the late Mr. Carden of this city. In introducing this operation, he won for himself a lasting repute for originality, ingenuity, and skill; and I am sure that, in expressing a deep regret at the absence from among us this day of so accomplished and able a surgeon, so wise in council and full of resource, in whom, in truth, were to be found all the qualities of a great surgeon, I only feebly, perhaps, give utterance to the thoughts of all those who knew him, appreciated him, and had the privilege of his friendship.

Gritti's operation undoubtedly owes its parentage to that of Carden ; but, although the retaining of the patella and consequent preservation of the normal attachments of the extensors of the leg is a plan as good as it was original with Gritti, still the details of this method prevented the realisation of those advantages which in principle it embodied. Hence the modification which I have ventured to term "supracondyloid amputation "- -an operation which, retaining the advantages of Gritti's method, eliminates its defects by lengthening the anterior flap, forming a posterior flap one-third in length of the anterior one, suturing the patella and femur together; and, lastly, and most important of all, by making a high femoral section, but one not involving the medullary canal.

The special advantages that may be claimed for supracondyloid amputation are :

I. That the posterior surface of the anterior flap being covered with a natural synovial membrane, the chances of suppuration and purulent absorption are diminished.

2. Any possibility of the split patella shifting from its place on the cut surface of the femur is prevented by the high femoral section, and by suturing the two bones together.

3. The vessels are divided at right angles to their continuity, and not obliquely, as in other flap operations.

4. The existence of a posterior flap diminishes the chances of any wide gaping of the wound; while the anterior flap, being oval, increases the chances of the stump tapering gradually towards its extremity and assuming the form of a rounded cone.

5. The preservation of the normal attachments of the extensors of the leg.

These advantages embody those of both flap and circular amputation of the thigh, and, at the same time, eliminate their defects.

Although there are many other surgical topics of interest and im. portance I should wish to discuss, did time permit, there is one bearing directly on surgical progress which, though it must be but briefly alluded to, I wish particularly to mention. Recently, all who have at heart 
the progres of scientific medicine and surgery must have rojoiced at the formation of the Association for the Advancement of Medicine by Revearch. This step augurs well for the future of physiology-the science which is not alone the foundation, but also the framework of sureery, as it is also of medicine and pathology.

At the opening meeting of the Association, Sir George Jessell (the Master of the Rolls) well remarked that there are two things the public require to be instructed in-one, that the future progress of medicine must rest on science; and the other, the necessity for experiments on animals. The great practical difficulty, however-one which, I hope, in time will be overcome-is that the Association will have to deal with a section of the public who refuse to be instructed; refuse to recognise established facts ; refuse to weigh evidence ; rubstitute groundless assertion for argament ; and wilfully and deliberately accuse the scientific physiologist of a selfishness and cruelty as heartless as it is cowardly. In creating so unjust a prejudice, there is in some instances, doubtless, an unconscious, but in many others, I fear, a wilful attempt to pervert the moral sense of the public. It will be no light task for the Association to instruct such persons, whose wrath is reserved-not for the sportsman, gourmet, or military tyrant, but for the physiologist, who is outlawed if he does not fulfil all the vexatious conditions of an extraordinary Act, the passing of which was simply an insult to our profession, whose aim is ever, not to cause suffering, but to relieve it-not to destroy life, but to save it; and who are ever ready willingly to im. peril, and often, with true heroism, do lay down their own lives to save one that is, perhaps, worthless to all but the possessor of it. If in this contention a heartless cruelty is found, on which side is it? Is it with those whose objects I have indicated, or with those who hinder and thwart the realisation of them?

It has been stated with the inaccuracy that, as a rule, characterises the utterances of, in many instances, perhaps, well-meaning, but not the less essentially mischievous section of the community, that takes so keen a pleasure in discrediting experimental physiology, that no prac. tical benefit has accrued to medicine or surgery from it. I would, leaving what has been done in this direction in medicine to other and abler hands, suggest to their consideration a study of Mr. Gamgee's recently published and able work on The Infuence of Vivisection on Humare Surgery. In this, it will be seen that many of the most im. portant developments of surgery are the direct outccme of physiological experiment-as, for example, subcutaneous surgery, arterial ligation, torsion, transfusion, the introduction of the ecraseur, periosteal preservation, artificial respiration; and, among others, such operations as nephrectomy, ovariotomy, excision of pylorus, and amputation at the hip-joint ; and last, but not least, the introduction of the hypodermic injection of various medicinal agents.

It seems, however, and with shame we must confess it, that we are living in an epoch in which the labours and achievements of the greatest physiologists and surgeons, both living and dead, were forgotten and ignored; and for those who endeavour, even at a long interval, to follow in their steps, the statute, which is a blot in the history of scientific progress in England, has been enacted, and enacted by those who are every day only too willing to avail themselves of the great advantages resulting from labours which now cannot be continued, save under restrictions which are well-nigh intolerable. Professor Tyndall has well said that, "however noisy the fanaticism of the moment may be, the common sense of Englishmen will not, in the long run, permit it to enact cruelty in the name of tenderness, or to debar us from the light and leading of such investigations." The great fact to be taught, the great fact to be learned, is, that to experimental physiology must we chiefly look for the mens of lighting the paths traversed by those who work in the van of medical and surgical progress; who work conscious that, compared to what may be hoped for in the future, the advances already made are only-as Newton said of his greatest achievementslike those of 2 child playing with the waves as they break upon the sand. But,

$$
\text { To strive, to seek, to find, and not to yield," }
$$

they still labour to realise the fair aspiration that the book of Life may yet be read, not by the dim and flickering rass of opinion, but by the clear and steady light of ascertained fact. Seeking for means to baffle those diseases, fruitful sources of so much sin and sorrow, that up to this have defied our best directed efforts to destroy. Earnestly striving to reseue medicine and surgery from the mists and shifting quicksands of mere clinical observation, and fix them on the foundation of science, and who, ever yearning, like Goethe, for "Light-more light", patiently seek in the exhaustless world of Nature for the golden grains of truth.

Are these efforts to be thwarted and hindered in the country of Harvey and Jenner? It has been well said by Jellett, that "the place which our country holds among nations must be fixed by the labours of her children; that their success is her glory ; that their defeat or dishonour must fall darkly upon her." On us it devolves to see that nothing is done that may render such defeat possible; nothing done that will allow the laurels of scientific medicine to be cruelly snatched from us and transferred to other countries and other peoples. This may, perhaps, be called a selfish form of patriotism. Perhaps it is ; but, if so, I would ask, need we be ashamed of it ?

I have mentioned many achievements in surgery the past half century has witnessed. Fifty years hence, this great Association will, I hope meet here again to celebrate its centenary; and my successor will, I trust, with greater ability and eloquence than I can command, tell of as great or greater triumphs than I have done. To enable him to do so we can all aid, some powerfully, others feebly ; but still every unit in this great brotherhood can assist; and it should be our ambition 25 well as our prayer that, when the hour arrives for us to cease from our work, we may all feel, on looking back on our lives, that we have done something to that end. Something - be it great or small-in the interests of our common humanity, in the interests of our loved country, and of a pure devotion to truth, to render the science to which we have devoted our lives, nobler and fairer than before.

\section{AN ADDRESS}

DELIVERED AT TIEE OPENINC OF

THE SECTION OF MEDICINE.

At the Annual Meeting of the Britisit Medical Association, in Worcester, August 1852.

By T. CLIFFORD ALLBUTT, M.A., M.D., F.R.S., Senior Physician to the General Infirmary, Leeds, etc.; President of the Section

MODERN FREEDOM OF THOUGHT, AND ITS INFLUENCE ON THE P'ROGRESS OF MEDICINE.

GENTLEMEN,-Fifty years of patient and self-forgetful toil have passed over the field of medicine since the foundation of this Society. Now, as then, we stand looking upon a boundless and unvintaged land, yet our fifty years of husbandry have not been unkindly nor our hands unfilled with plenty.

We may say, indeed, in this later time that the gleanings of Ephraim are more than the vintage of Abiezer; for, as Hastings, kindling with the new spirit of his time, was both its child and its leader, so this society which he founded has been both the product and the organ of a wondrous increase in scientific medicine. What is that spirit-that aflatus aliguis divirus - which in this century has expanded and transfigured our art? It is not the new power of unity alone-that strange new function which is bred in gatherings of men, a thing higher and other than the mere addition of individual faculties; this union the press and the railway have made possible; but there is that something more which has made these means-some masterful expansion which has widened the life and nerved the arm of modern science; which has given breadth to our thought, stuff to our logic, reality and endurance to our doctrines-whence comes this ? This comes, gentlemen, of the gift, without which all other gifts are but as apples of the Dead Seathe gift of freedom. The withes whereby for a thousand years men were bound in body and soul are broken; the dissolution of that tyranny which stalked, haltered, and baited the man who dared to think for himself is fulfilled in our own time, and no longer is it declared to men, "Thus, and thus only, shalt thou think of God and Nature!"

Man has won three victories: he has ranquished the terrors of the old world, brought forth food, warmth, and light upon the face of it, and thus ceased to be Caliban, the earth slave. Then man became a nation; nations strove for the mastery and political freedom; his second victory was won.

Lastly, with the earth his servant and his civil rights secured, the final and crowning work remained, to win the freedom of his mind. Modern civilisation has much to answer for, but it is a glorious thing to live in the first years of perfect freedom ; nay, even to live in perhaps the first generation since Pericles, which has dared wholly to cast off the dominion of external authority and to think for itself. Upon a narrow foundation and under transient conditions in Hellas, this com- 